\title{
An opportunity for improvement with a medication reconciliation programme
}

\author{
Ana Belén Jiménez-Muñoz ${ }^{1}$, Ana Clara Zoni ${ }^{2}$, Esther Duran-Garcia ${ }^{2}$, Paz Rodriguez Pérez ${ }^{2}$, \\ María Sanjurjo Saez ${ }^{2}$, Rosa Pla-Mestre ${ }^{2}$ \\ ${ }^{1}$ Preventive Medicine, Hospital Universitario Severo Ochoa, Madrid, Spain \\ ${ }^{2}$ Preventive Medicine and Quality Management Department, Hospital General Universitario Gregorio Marañón, C/Doctor Esquerdo, \\ Madrid, Spain \\ Email: *ana beleb.jimenez@salud.madrid.org, aclara.zoni@salud.madrid.org,mduran.hgugm@salud.madrid.org, \\ prodriguezpe.hgugm@salud.madrid.org,msanjurjo.hgugm@salud.madrid.org, rosa.pla@salud.madrid.org
}

Received 16 July 2013; revised 16 August 2013; accepted 23 August 2013

Copyright @ 2013 Ana Belén Jiménez-Muñoz et al. This is an open access article distributed under the Creative Commons Attribution License, which permits unrestricted use, distribution, and reproduction in any medium, provided the original work is properly cited.

\begin{abstract}
Medication reconciliation is priority in safety. Between $54 \%$ and $67 \%$ of hospitalized patients have at least one unintended discrepancies (UDs) between pharmacological treatment of a hospital inpatient and treatment that they were previously taking at home. Quasi-experimental pre-post study performed. The objective is to assess the impact of an intervention aimed at decreasing UDs between medication prescribed on admission and patient's regular treatment. Patients who were hospitalised for more than 24 hours and were undergoing treatment prior to admission which involved taking three or more medicines were included. The number of patients included was 331 and 3781 medicines were reconciled. The incidence of UDs decreased significantly from $7.24 \%$ to $4.18 \%$. Omission was the most common UD, with a significant decrease from $5.8 \%$ to $3.4 \%$. Respect to clinical impact, we observed that error type C (error reached patient without causing harm) predominates, however, experienced a statistically significant decrease from $5.3 \%$ to $2.4 \%$.
\end{abstract}

Keywords: Medication Reconciliation; Admission; Unintended Discrepancies

\section{INTRODUCTION}

Nowadays it is very common to find differences between the pharmacological treatment of a hospital inpatient and the treatment that they were previously taking at home, as a result of which any difference found is defined as a

"Corresponding author. discrepancy. The large majority of these discrepancies are accounted for changes in the clinical condition of the patient. However, more than half of hospital inpatients have at least one unintended discrepancy (UD). Any UD is considered to be medication error. Furthermore, half of all of these have sufficient potential to cause harm [1]. As is to be expected, polymedicated patients are precisely those who are most vulnerable, not only because the probability of being the victim of an error in their medication becomes greater as the number of drugs taken increases, but also because these patients are, for the most part, older people with multiple pathologies and/or chronic patients who need to be admitted to hospital more frequently [2].

Transitions between different levels of care have been identified as high-risk points for medication errors occurring. Establishments which are affected the most are those which do not have a dedicated person in charge of the reconciliation process and/or which lack IT applications that communicate between the different levels of care [3].

Medication reconciliation is understood as the formal process by which the complete and exact list of a patient's prior medication is assessed together with their pharmacotherapeutic prescription following a care transition $[2,4]$.

The majority of international agencies which are at the forefront of patient safety consider the implementation of medication reconciliation programmes in hospitals as a priority in their guidelines [5-7].

In spite of the importance of the subject, medication reconciliation today remains a significant challenge. Through an appropriate reconciliation programme, around $80 \%$ of errors relating to medication and the potential 
harm caused by these could be reduced [8,9]. This would also provide an opportunity to reassess regular treatment when the medical condition of a patient changes. In turn, medication reconciliation on admission makes it easier for the patient's basic treatment to be taken into account on discharge [10].

The objective of this study is to assess the impact of an intervention aimed at decreasing UDs between medication prescribed on admission to hospital and a patient's regular treatment.

\section{METHODOLOGY}

\subsection{Design}

A quasi-experimental pre-post study with no equivalent control group performed from June 2009 through May 2010 (3-month first phase, 6-month intervention, and 3month second phase). We selected two inpatient departments: a general surgery department (GS) and an internal medicine department (IM).

We designed a data-gathering sheet with variables relating to the patient's clinical details, drug history, medication prescribed and discrepancies detected. At the First Phase of the Study, the nursing staffs interviewed inpatients (asked about their medical history). Then, the pharmacists examined the prescription issued by the staff doctor at the time of admission (IM) or after surgery (GS). They compared those prescriptions, with those recorded in the interview. The data-gathering sheet was used to record the prescription at the time of admission, the discrepancies detected, and the severity of those discrepancies. At the Second Phase, we designed and APLICON reconciliation tool. With this tool, doctors who are prescribing medicines have access to details of all the medicines that the patient was taking prior to admission. At the last Phase of the Study the same interview technique was used, except patients' routine medication data was recorded using the computer reconciliation tool. Pharmacist's Assessment was carried out using the computer programme too.

The research team was made up of: specialist doctors in preventative medicine, pharmacists, nurses and an inpatient unit medical coordinator.

\subsection{Setting and Population}

The Gregorio Marañón Hospital (HGUGM) is a public hospital in Madrid (Spain). It is classified as a third-level hospital, with 1500 beds and 7000 professionals who provide healthcare to 450,000 people.

In order to carry out this study, two hospital inpatient units were chosen which were representative of the type of patients who use the hospital: a general surgery (GS) unit and an internal medicine (IM) unit. In both units, patients were included who were hospitalised for more than
24 hours and who were undergoing treatment prior to admission which involved taking three or more medicines. Patients excluded were those who were unable to communicate for themselves and who had no carer, those who were transferred from another medical department and those being cared for by another hospital inpatient unit. This study was approved by the Ethics Review Board of the Gregorio Marañón Hospital.

\subsection{Statistical Methods}

The main outcome for the results was the cumulative incidence (I) of unintended discrepancies (UD), defined as the total number of UDs over the total drugs prescribed expressed as a percentage. The second principal outcome was the proportion of patients with at least one UD.

Associations between the variables were tested with Chi-square test, Fisher's exact test, Student's T test and the Mann-Whitney $U$ test regarded as significant when the $p$ value was less than 0.05 . Data were analysed with SPSS version 18.0.

\subsection{Discrepancy Measurement System}

\section{Stage I: Before the Intervention}

On a daily basis, the nursing staff, undertook interviewing of all patients who were being admitted to the unit, and had given the inform consent to participate in the study. The variables collected were grouped into personal information about the patient, pathological history, usual medication, treatment adherence checks, type of admission and time of interview.

The pharmacists also evaluated the first prescription written by the doctor. In this stage, the doctors who were responsible for the patients were not aware of the true objective of this study. The pharmacists went through this prescription comparing it drug by drug to the medications recorded during the nursing interview. The discrepancies detected were classified according to the system described by Delgado Sánchez [2]. If a UD was detected, the pharmacist suggested a change to the doctor responsible. The medical impact of the discrepancies was assessed by consensus between the pharmacist and the head of the unit, based on a standardised classification [11].

\subsection{The Intervention}

Clinical Sessions: Staff was shown the results concerning discrepancies, and concerning the usefulness of a medication reconciliation tool.

Medication reconciliation tool (APLICON): an IT application was designed which included all of a patient's usual medication in connection with the electronic prescription programme. This allowed doctors to make a recommendation for each individual drug: whether to con- 
tinue with it, stop altogether, stop temporarily or change to a different treatment [12].

\section{Stage II: After the Intervention}

In order to evaluate and classify discrepancies and their medical impact, the same method was followed as for the previous stage, except that the IT tool was used.

\section{RESULTS}

481 patients were interviewed during the two stages of the study. The total number of patients included was 331 (68.8\%). The main reason for exclusion was less than 3 medicines being taken as part of the patient's normal treatment. Table 1 describes the characteristics of the study population. In the comparative analysis of the population before and after the intervention, no statistically significant differences were found with respect to average age, gender, comorbidity or toxic habits. However, in measuring the post-intervention group, a greater significant proportion of patients over the age of 65 was observed $(75 \%)$ than in the group of patients in stage I (66\%).

With respect to drugs, a total of 3781 medicines were reconciled. The median number of drugs per patient in the first stage was 10 medicines compared to 12 medicines in the second stage. A higher significant proportion of patients taking more than 10 drugs were observed in stage II (75.8\%) than in stage I (63.2\%).

Following the intervention, the incidence of UDs with respect to the total number of drugs decreased significantly from $7.24 \%$ to $4.18 \%$ (Table 2 ). The distribution according to type of discrepancy can be seen in Table 3. Omission is the most common UD, with a significant decrease from $5.8 \%$ before the intervention to $3.4 \%$ afterwards.

Table 1. Characteristic of the study population.

\begin{tabular}{ccc}
\hline & Stage 1 N = 174 & Stage 2 N = 154 \\
\hline Median age (years) & 74 & 75 \\
Gender (Male) & $53.4 \%$ & $51 \%$ \\
Most common comorbidities & HTN (52.9\%) & HTN (65\%) \\
& DLP (32.8\%) & DLP (35\%) \\
Day of admission (Working day) & $82.1 \%$ & $84.1 \%$ \\
Type of admission (Emergency) & $59.2 \%$ & $52.9 \%$ \\
Median drugs per patient & 10 & 12 \\
Patient taking 3 - 5 drugs & $6.3 \%$ & $0.6 \%$ \\
Patient taking 5 - 9 drugs & $30.5 \%$ & $23.6 \%$ \\
Patient taking > = 10 drugs & $63.2 \%$ & $75.8 \%$ \\
\hline
\end{tabular}

HTN: Hypertension. DLP: Dyslipidemia. ${ }^{*} \mathrm{p}=0.001$ (between stage1-stage 2).
Table 2. Comparison of total discrepancies.

\begin{tabular}{cccc}
\hline Type of discrepancy & Stage 1 & Stage 2 & p value \\
\hline Total discrepancy & 1483 & 1475 & - \\
Number of ID & 1351 & 1393 & - \\
- Cumulative incidence & $74.1 \%$ & $71.1 \%$ & 0.05 \\
- $\quad$ Average ID per patient & 7.8 & 8.8 & 0.00 \\
Number of UD & 132 & 82 & - \\
- Cumulative incidence & $7.2 \%$ & $4.2 \%$ & 0.00 \\
- $\quad$ Average UD/P & 0.8 & 0.5 & 0.06 \\
\hline
\end{tabular}

ID: Intended discrepancy. UD: Unintended discrepancy. P: Patient. I: Cumulative Incidence.

Table 3. Distribution according to type of discrepancy.

\begin{tabular}{|c|c|c|c|}
\hline Type of discrepancy & $\begin{array}{c}\text { Stage } 1 \\
\text { cumulative } \\
\text { incidence }\end{array}$ & $\begin{array}{c}\text { Stage } 2 \\
\text { cumulative } \\
\text { incidence }\end{array}$ & p value \\
\hline $\begin{array}{l}\text { ID: Start due to } \\
\text { medical condition }\end{array}$ & 39.7 & 44.2 & 0.00 \\
\hline $\begin{array}{l}\text { ID: Not prescribed or } \\
\text { change to method of } \\
\text { administration/frequency/dose }\end{array}$ & 32.1 & 25.0 & 0.00 \\
\hline $\begin{array}{l}\text { ID: Substitution based on } \\
\text { guidelines }\end{array}$ & 2.2 & 1.7 & 0.25 \\
\hline UD: Omission of medicine & 5.8 & 3.4 & 0.00 \\
\hline $\begin{array}{l}\text { UD: Differences in method of } \\
\text { administration/frequency/dose }\end{array}$ & 0.7 & 0.7 & 0.98 \\
\hline UD: Duplicate treatment & 0.4 & - & 0.01 \\
\hline $\begin{array}{l}\text { UD: Start treatment without } \\
\text { medical explanation }\end{array}$ & 0.3 & 0.05 & 0.18 \\
\hline $\begin{array}{l}\text { UD: Medicine unavailable, } \\
\text { no Alternative treatment }\end{array}$ & 0.05 & - & 0.97 \\
\hline UD: Different medicine & 0.05 & - & 0.97 \\
\hline UD: Counter-indication & 0.05 & - & 0.97 \\
\hline
\end{tabular}

ID: Intended discrepancy. UD: Unintended discrepancy.

With respect to the clinical impact of the UDs, we observed that error type $C$ (the error reached the patient without causing harm) predominates; however there was a statistically significant decrease from $5.3 \%$ to $2.4 \%$ following the intervention (Table 4).

On analysis of the characteristics of the population which experienced UDs, no significant association was found with certain variables of interest such as age, gender, day of admission, hypertension, heart failure, dyslipidemia, COPD, diabetes mellitus, thyroid problems or depression. Significant differences were found among patients with asthma who have a greater proportion of UDs (54.8\%) in comparison to non-asthmatic patients (29.5\%), and among patients suffering from ulcer/reflux (52.5\%) compared to patients who do not have this condition (28.5\%). No significant association was found with type of admission (emergency and non-emergency). 
Table 4. Clinical impact of unintended discrepancies.

\begin{tabular}{cccc}
\hline Seriousness & $\begin{array}{c}\text { Stage 1 } \\
\text { cumulative } \\
\text { incidence }\end{array}$ & $\begin{array}{c}\text { Stage 2 } \\
\text { cumulative } \\
\text { incidence }\end{array}$ & p value \\
\hline A-No error, only possibility & 0.4 & & 0.00 \\
$\begin{array}{c}\text { B-Did not reach patient } \\
\text { C-Reached patient, }\end{array}$ & 0.3 & 0.1 & 0.64 \\
$\begin{array}{c}\text { no harm caused } \\
\text { D-Reached patient, } \\
\text { required monitoring }\end{array}$ & 5.3 & 2.45 & 0.00 \\
$\begin{array}{c}\text { E-Temporary harm } \\
\text { Tem }\end{array}$ & 0.4 & 0.76 & 0.18 \\
\hline
\end{tabular}

The most common treatment groups displaying UDs were antihypertensives and psychiatric drugs (16.5\%), followed by hypolipidemics (9.5\%). However, when the pharmacological group with UD is adjusted according to the prescription frequency of each one, other pharmacological groups representing a risk are identified: topical dermatological treatment (3/5, 60\%), ophthalmology medications $(14 / 27,52 \%)$, antineoplastics and immunomodulators $(3 / 7,53 \%)$, medicines for treating bone diseases and calcium $(12 / 49,24 \%)$ and hypolipidemics (20/116, 17\%).

\section{DISCUSSION}

The medication reconciliation programme has proved to be an effective tool. Following the intervention we reduced the incidence of UDs. This result is even more relevant if we take into consideration that the post-intervention population was composed of a greater proportion of people who were taking more than 10 drugs as their usual treatment, and also a greater proportion of people over the age of 65 , both factors bring related to a greater probability of errors arising [13,14].

There are few published works in Spain which study error incidence. Delgado Sánchez et al. [15] carried out a multicentre study among 603 patients, in which the incidence of UDs found was 13.9\%. Páez Vives et al. [16] carried out a multicentre study with 469 patients in which the incidence of reconciliation errors was $18.48 \%$. We found a lower incidence of errors compared to the previous studies. This could be related to the fact that one of the inclusion criteria for the studies referred to was that patients were over the age of 65 , which is linked to an increased probability of errors. The proportion of patients with at least one UD was $35.6 \%$ in stage 1 and $26.7 \%$ in stage 2 . International publications display a range between $21 \%$ to $53.6 \%[9,17,18]$.

As regards the type of error committed, omission was the most frequent $(78.5 \%-81 \%)$, which coincides with the majority of research published and displays a range of $26.8 \%$ to $72 \%$ [15,17,19,20].
In terms of the seriousness of UDs, both in our study and in the majority of published works, the most common type is type C [18,21]. It is important to take into account that we only assessed UDs and their seriousness at the time when the patient was admitted. Pippins et al. [22] mention in their work that the majority of errors involving potential harm occur on discharge, compared to errors committed on admission. A particular error which is classified as having a low potential for causing harm on admission could be classified as an error with a greater potential for harm on discharge; this is largely due to the difference in care and monitoring when the patient is in hospital.

On analysis of the population with UDs, we did not find any significant relationship with certain factors of interest such as age, number of medicines or day on which patients were admitted, as is described in other works [22]. Nonetheless, it can be observed that for patients with asthma or with ulcers, it is more probable that a UD will occur. Unfortunately, the relationship between UDs and chronic diseases has not been widely studied [23,24]. More research needs to be carried out regarding the diseases for the purpose of identifying high-risk patients.

In spite of the fact that the pharmacological groups with the greatest number of UDs, Paez Vives [16] indicates antiulcerants, diuretics and hypolipidemics. Cornish et al. [18] point to cardiovascular medications and drugs for treating the central nervous system. However, Pippins et al. [22] distinguish between medicines with the most reconciliation errors (cardiovascular, respiratory system, hypolipidemics) and those which have a high risk of error adjusted according to their frequency of prescription (anti-gout drugs, muscle relaxants, antidepressants, hypolipidemics) as we did in our study.

In terms of the study design, one limitation was the impossibility of carrying out the interviews during the same months of the year. The fact that the post-intervention population was taking a greater quantity of medicines than the population prior to the intervention could be related to the seasonal variation: summer-autumn for the first stage, and winter-spring for the second. A possible further limitation could be based on account of the doctors feeling aware of being observed - the Hawthorne effect-which might have led to changes to their normal practices. In order to reduce this, the observation was hidden in the first stage, and that assessment of the seriousness of UDs was carried out with the collaboration of the head of the unit. As a third limitation, it must be noted that the study focused solely on errors arising on admission, given that it would be unethical not to rectify any error detected. This could have caused the seriousness of any errors to be reduced. As it is, it is considered that the data from the present study has external validity due to 
the fact that the study was carried out in two clinical departments, which were representative of both medical and surgical units.

Although a patient's normal medication is recorded on various occasions and by different professionals, it is often the case that this information is fragmented in various different documents in their medical record, and more importantly, that it cannot be accessed quickly and unambiguously when it comes to prescribing. Having this information available at that time for making treatment decisions is without a doubt, a vital element for improving the safety or our patients. The current development of communications technology, in particular having access to information about treatments prescribed at the level of primary healthcare, represents an element which is sure to facilitate the reconciliation process substantially. However, it must be taken into account that this cannot in any respect mean phasing out the in-depth clinical interview, which allows medical professionals to assess adherence to treatment or the consumption of parapharmaceutical products which are ever more abundant [25]. Interviews also ensure thoroughness in an environment in which not all of the population uses public primary healthcare services.

\section{REFERENCES}

[1] Tam, V.C., Knowles, S.R., Cornish, P.L., Fine, N., Marchesano, R. and Etchells, E. (2005) Frequency, type and clinical importance of medication history errors at admission to hospital: A systematic review. CMAJ, 173, 510515. http://dx.doi.org/10.1503/cmaj.045311

[2] Delgado Sánchez, O., Anoz Jimenez, L., Serrano Fábia, A. and Nicolas Pico, J. (2007) Conciliación de la medicación (Medication Reconciliation). Medical Clinics (Barc), 129, 343-348. http://dx.doi.org/10.1157/13109550

[3] Bandrés Liso, A., Villar Fernández, I., Beloqui Lizaso, J., Izuel Rami, M., Arenere Mendoza, M. and Aza Pascual, M. (2008) Programa de farmacéuticos de enlace para mejorar la conciliación en la transición entre niveles asistenciales. (Implementation of a programme of link pharmacists to improve the medication reconciliation in the transition between health care levels). Farmacia Hospitalaria, 192, 45-51.

[4] Rogers, G., Alper, E., Brunelle, D., Federico, F., Fenn, C.A., Leape, L.L., et al. (2006) Reconciling medications at admission: Safe practice recommendations and implementation strategies. Joint Commission Journal on Quality and Patient Safety, 32, 37-50.

[5] Joint Commission on Accreditation of Healthcare Organization. Hospital (2011) National Patient Safety Goals. http://www.jointcommission.org/assets/1/6/NPSG EPs S coring_HAP_20110706.pdf

[6] World Health Organization (2007) Collaborating centre for patient safety solutions. Assuring medication accuracy at transitions in care 2007. http://www.who.int/patientsafety/solutions/patientsafety/

\section{PS-Solution6.pdf}

[7] National Institute for Health and Clinical Excellence (NICE)/National Patient Safety Agency (NPSA) (2007) Technical patient safety solutions for medicines reconciliation on admission of adults to hospital. http://guidance.nice.org.uk/index.jsp?action=download\& $\underline{0}=38560$

[8] Rozich, J.D., Howard, R.J., Justeson, J.M., Macken, P.D., Lindsay, M.E. and Resar, R.K. (2004) Standardization as a mechanism to improve safety in health care. Joint Commission Journal on Quality and Patient Safety, 30, 5-14.

[9] Gleason, K.M., Groszek, J.M., Sullivan, C., Rooney, D., Barnard, C. and Noskin, G.A. (2004) Reconciliation of discrepancies in medication histories and admission orders of newly hospitalized patients. American Journal of Health-System Pharmacy, 61, 1689-1695.

[10] Arroyo Domingo, E. (2008) Transiciones entre niveles asistenciales: Puntos críticos de actuación farmacéutica para conciliar la medicación de los pacientes (Transitions between levels of care: critical points for pharmaceutical action to reconcile patient medication). Farmacia Hospitalaria, 192, 52-58.

[11] Otero López, M.J., Codina Jané, C., Tamés Alonso, M.J. and Pérez Encinas, M. (2003) Errores de medicación: Estandarización de la terminología y clasificación (Medication errors: The standardisation of terminology and classification). Results of the Ruiz-Jarabo 2000 Grant. Farmacia Hospitalaria, 27, 137-149.

[12] Giménez Manzorro, A., Zoni, A.C., Rodríguez Rieiro, C., Durán García, E., Trovato López, N., Pérez Sanz, C., et al. Developing a programme for medication reconciliation at the time of admission into hospital. International Journal of Clinical Pharmacy. http://dx.doi.org/10.1007/s11096-011-9530-1

[13] Agrawal, A. and Wu, W.Y. (2009) Reducing Medication errors and improving systems reliability using an electronic medication reconciliation system. Joint Commission Journal on Quality and Patient Safety, 35, 106-114.

[14] Lessard, S., DeYoung, J. and Vazzana, N. (2006) Medication discrepancies affecting senior patients at hospital admission. American Journal of Health-System Pharmacy, 63, 740-743. http://dx.doi.org/10.2146/ajhp050291

[15] Delgado Sánchez, O., Nicolás Pico, J., Martınez López, I., Serrano Fabia, A., Anoz Jiménez, L., Fernández Cortes, F. (2009) Errores de conciliación en el ingreso y en el alta hospitalaria en pacientes ancianos polimedicados. Estudio prospectivo aleatorizado multicéntrico (Reconciliation errors on hospital admission and discharge of older polymedicated patients. A multicentre prospective randomised study). Medical Clinics, 133, 741-744. http://dx.doi.org/10.1016/j.medcli.2009.03.023

[16] Páez Vives, F., Recha Sancho, R., Altadill Amposta, A., Montaña Radu, R., Anadón Chorto, N. and Castells Salvado M. (2010) Abordaje interdisciplinar de la conciliación crónica al ingreso en un hospital (An interdisciplinary approach to chronic reconciliation at hospital admission). http://dx.doi.org/10.1016/j.cali.2010.03.002

[17] Vira, T., Colquhoun, M. and Etchells, E. (2006) Reconcilable differences: Correcting medication errors at hospital 
admission and discharge. Quality \& Safety in Health Care, 15, 122-126.

http://dx.doi.org/10.1136/qshc.2005.015347

[18] Cornish, P.L., Knowles, S.R., Marchesano, R., Tam, V., Shadowitz, S., Juurlink, D.N., et al. (2005) Unintended medication discrepancies at the time of hospital admission. Archives of Internal Medicine, 165, 424-429. http://dx.doi.org/10.1001/archinte.165.4.424

[19] Jiménez Muñoz, A.B., Muiño Miguez, A., Rodriguez Perez, M.P., Vigil Escribano, M.D. and Duran Gracia, M.E. (2010) Medication error prevalence. International Journal of Health Care Quality Assurance, 23, 128-139.

[20] Pastó Cardona, L., Pàez Vives, F., Schönenberger Arnaiz, J.A., Gorgas Torner, M.Q. and Codina Jané, C. (2009) Estudio de incidencia de los errores de medicación en los procesos de utilización del medicamento: Prescripción, transcripción, validación, preparación, dispensación y administración en el ámbito hospitalario (A study of the incidence of medication errors in medicine use processes: Prescription, transcription, validation, preparation, dispensation and administration in hospitals). Farmacia Hospitalaria, 33, 257-268. http://dx.doi.org/10.1016/S1130-6343(09)72465-1
[21] Coffey, M., Cornish, P., Etchells, E. and Matlow, A. (2009) Implementation of admission medication reconciliation at two academic health sciences centres: Challenges and success factors. Healthcare Quarterly, 12, 102-109. http://dx.doi.org/10.12927/hcq.2009.20719

[22] Pippins, J.R., Gandhi, T.K., Hamann, C., Ndumele, C.D., Labonville, S.A., Diedrichsen, E.K., et al. (2008) Classifying and predicting errors of inpatient medication reconciliation. The Journal of General Internal Medicine, 23, 1414-1422. http://dx.doi.org/10.1007/s11606-008-0687-9

[23] Ledger, S. and Choma, G. (2008) Medication reconciliation in hemodialysis patients. CANNT Journal, 18, 41-43.

[24] Persell, S.D., Bailey, S.C., Tang, J., Davis, T. and Wolf, M. (2010) Medication reconciliation and hypertension control. American Journal of Medicine, 123, 182.e9182.e15.

[25] Delgado Sánchez, O., Martínez López, I., Crespí Monjo, M. and Serra Soler, G. (2008) Conciliación de la medicación: Asumamos la responsabilidad compartida (medication reconciliation: Assuming shared responsibility). Farmacia Hospitalaria, 32, 63-64. http://dx.doi.org/10.1016/S1130-6343(08)72815-0 